\title{
Dendritic cell vaccine with Ag85A enhances anti-colorectal carcinoma immunity
}

\author{
JINGBO ZHAI ${ }^{1-3}$, WEI GAO ${ }^{1,3}$, LEHENG ZHAO ${ }^{1,3}$, ZHIPENG GAO $^{4}$, XUEFENG JIANG ${ }^{2}$ and CHANGLONG LU $^{1-3}$ \\ ${ }^{1}$ Brucellosis Institute of Inner Mongolia University for The Nationalities, Tongliao, Inner Mongolia 028000; \\ ${ }^{2}$ Department of Immunology, China Medical University, Shenyang, Liaoning 110122; \\ ${ }^{3}$ Brucellosis Prevention and Treatment Engineering Technology Research Center of Inner Mongolia Autonomous Region, \\ Tongliao, Inner Mongolia 028042; ${ }^{4}$ Department of Urology, The First Hospital of China Medical University, \\ Shenyang, Liaoning 110001, P.R. China
}

Received April 24, 2018; Accepted August 31, 2018

DOI: $10.3892 /$ etm.2018.6851

\begin{abstract}
Dendritic cells (DCs) are able to trigger T-cell activation and thus have been considered important for vaccine production against cancers. Vaccines containing DCs have been reported to be effective for developing immunity against cancer cells. The interactions between DCs and auxiliary agents are critical in the development of second-generation vaccines. In the present study, it was evaluated whether Ag85A-mixed DCs could enhance anti-tumor immunity in laboratory mice with colorectal carcinoma. Functional and phenotypic analyses of the effects of Ag85A-mixed DCs were conducted via flow cytometry and measurement of T-cell proliferation. In addition, interferon (IFN) $-\gamma$ production was assessed. The therapeutic efficacy of DC vaccination for colorectal carcinoma treatment in mice was investigated. It was identified that Ag85A-mixed DCs exhibited strong upregulation of CD80, CD86 and major histocompatibility complex class II. Cytotoxic T-lymphocytes with CT26-primed Ag85A-DCs were indicated to induce stronger responses against CT26 tumor cells and trigger IFN- $\gamma$ production. Furthermore, the Ag85A-mixed DC vaccine exerted a considerable inhibitory effect on tumor progression in mice as compared with the control group. Therefore, DCs in combination with the Ag85A gene may reinforce anti-colorectal carcinoma immunity. The current study provides a novel potential strategy for cancer treatment by enhancing immunity via Ag85A-mixed DC vaccination.
\end{abstract}

Correspondence to: Dr Changlong Lu, Brucellosis Institute of Inner Mongolia University for The Nationalities, 996 Xilamulun Street, Keerqin, Tongliao, Inner Mongolia 028000, P.R. China E-mail: luchanglongg@163.com

Key words: dendritic cells, antigen 85A, colorectal carcinoma, major histocompatibility complex class II

\section{Introduction}

Colorectal carcinoma (CRC) is currently the third most prevalent cancer type worldwide. It has a complex etiology that is influenced by both environmental and genetic factors (1). Colorectal cancer patients in the high-risk late stage (stage II or III) are treated with adjuvant chemotherapy in combination with fluoropyrimidine monotherapy, which reduces the risk of recurrence and death by approximately 20-30\% compared with fluoropyrimidine monotherapy $(2,3)$. Addition of oxaliplatin to this treatment regimen has been reported to improve disease-free survival in three individual landmark trials (4). Nevertheless, the side effects of this treatment have limited its application (5). Thus, there is an urgent requirement to explore novel therapeutic strategies against CRC. In the present study, an immunological treatment approach against CRC was investigated.

Immunization-based therapy thatutilizesantigen-presenting cells (APCs) to enhance efficacy is considered to be a promising approach for the treatment of cancer (6). Dendritic cells (DCs) serve prominent roles in various immunization therapies by activating cytotoxic T-lymphocytes (CTLs) $(7,8)$. The key role of DCs in cell-mediated immunity serves as the basis for the development of effective DC vaccines for immunization therapies against tumors $(9,10)$. This approach may induce certain immunological responses in cancer patients with prostate cancer (11), lymphoma (12), melanoma, bladder transitional cancer (13) and non-small cell lung carcinoma (14). A sufficient number of functioning DCs that are able to activate T-cells is important for the efficacy of DC vaccines (15). Specific carrier proteins, cytokines, immunological adjuvants and transgenic viruses have been demonstrated to influence the immune response activation by DCs (16). Previous studies have reported that non-methylated cytosine-guanine $(\mathrm{CpG})$ motifs may act as adjuvants for boosting tumor immunity by activating DCs. Treatment in which $\mathrm{CpG}$ motifs are applied may be achieved via upregulation of Th1 cytokines, soluble growth factors and primary DC surface markers $(17,18)$.

Antigen 85A (Ag85A) is involved in acid synthesis (19). Accumulating evidence has indicated that Ag85A may promote extensive proliferation of Th cells and the production of Th1 
cytokines in mice and mycobacterium-infected humans $(20,21)$. Laboratory rats injected with plasmid DNA harboring the Ag85A gene exhibited increased generation of interleukin (IL) -2 and interferon (IFN) $-\gamma$ and increased CTL activity in response to mycobacterium proteins in the Bacillus Calmette-Guérin vaccine $(22,23)$. Furthermore, injection with the Ag85A-mixed plasmid DNA vaccine protected mice from infection by Mycobacterium tuberculosis and resulted in stronger CTL activities (24). Immunization with DCs engineered with Mycobacterium Ag85A generated a distinct immune reaction profile, including CTL activity in response to antigenic determinants of Ag85A (25). Melanocytes collected from Ag85A-transfected B16-F10 mice were identified to inhibit tumorigenic effects and tumor progression (26). These findings demonstrate the potential use of Ag85A as an effective auxiliary agent for enhancing the immune response. However, the antitumor effects of Ag85A-mixed DCs against colorectal carcinoma remain unclear. Therefore, the present study examined whether treatment with Ag85A-transfected DC 2.4 cells could enhance the immunological response to colorectal cancer.

\section{Materials and methods}

Mice and cells. DC 2.4 cells were collected from C57BL/6 mice and infected with GM-CSF-transfected medullary cells with myc/raf oncogenes, as previously described (27). CT26 colorectal carcinoma (American Type Culture Collection, Manassas, VA, USA) and DC 2.4 cell lines were cultivated in RPMI 1640 (Gibco; Thermo Fisher Scientific, Inc., Waltham, MA, USA) at $37^{\circ} \mathrm{C}$ in an incubator under humid conditions with $50 \mathrm{ml} / 1 \mathrm{CO}_{2}$. C57BL/6 mice ( $\mathrm{n}=6$; male) aged 6-8 weeks (weight, 18-20 g) were obtained from the Chinese Academy of Science Shanghai Laboratory Animal Center (Shanghai, China). Animal experiments in this study were conducted in accordance with the internationally accepted principles for laboratory animal use and care. The study was approved by the Committee on the Ethics of Animal Experiments of China Medical University (Shenyang, China).

Ag85A plasmid transfection. Cells were transfected with $1 \mu \mathrm{g}$ Ag85A and pc-DNA3.1 (Shanghai GenePharma Co., Ltd., Shanghai, China) using Lipofectamine 2000 transfection reagent (Invitrogen; Thermo Fisher Scientific, Inc.). The pcDNA3.1+/Ag85A plasmid was incubated with Lipofectamine reagent for $20 \mathrm{~min}$ and subsequently added to the RPMI 1640 suspension containing DC 2.4 cells without antibiotics. The pcDNA3.1 vector without Ag85A served as the negative control. The Ag85A-DCs and mock-DCs were harvested at $48 \mathrm{~h}$ post-transfection.

Quantification of Ag85A mRNA expression. Total RNA was extracted from Ag85A-DCs using TRIzol reagent (Invitrogen; Thermo Fisher Scientific, Inc.). Reverse transcription (RT) was conducted using a Takara Prime Script RT reagent kit (Takara Biotechnology Co., Ltd., Dalian, China). Quantitative polymerase chain reaction ( $\mathrm{qPCR}$ ) was conducted using the Qiagen Quanti Tect SYBR Green PCR kit (Qiagen GmbH, Hilden, Germany) on an ABI 7300 Real-Time PCR system (Applied Biosystems; Thermo Fisher Scientific, Inc.). The thermocycling conditions were as follows: $3 \mathrm{~min}$ at $95^{\circ} \mathrm{C}$, followed by 45 cycles of $95^{\circ} \mathrm{C}$ for $15 \mathrm{sec}$ and $60^{\circ} \mathrm{C}$ for $60 \mathrm{sec}$. GAPDH served as the control for qPCR amplification. Analysis was performed in triplicate, and experiments were conducted at least three times. Analysis of relative gene expression was performed using the $2^{-\triangle \Delta \mathrm{Cq}}$ method (28). The following primers were used: GAPDH, sense, 5'-CAAAAGGGTCATCATCTCC-3' and antisense, 5'-CCCCAGCATCAAAGGTG-3'; Ag85A, sense, 5'-CAAAGTGGTGGTGCCAACTC-3' and antisense, 5'-CTC GCTGGTCAGGAAGGTCT-3'.

Assessment of primary surface markers. DCs were blocked using 5\% bovine serum albumin (Sigma-Aldrich; Merck $\mathrm{KGaA}$, Darmstadt, Germany) at room temperature for $1 \mathrm{~h}$ and incubated with CD16 and $32 \mathrm{mAb}$ (cat. nos. 2.4G2 and 565,502; 1:1,000; BD Biosciences, Franklin Lakes, NJ, USA) at $4{ }^{\circ} \mathrm{C}$ for $15 \mathrm{~min}$. Next, DCs were incubated in saturated PE-anti-MHC-II/CD80\&86 mAb (cat. no. 565157; 1:1,000; BD Biosciences) at $4^{\circ} \mathrm{C}$ for $30 \mathrm{~min}$. Cells were examined using a flow cytometer and were analyzed using FlowJo software 7.6.1 (FlowJo, LLC, Ashland, OR, USA).

Cytokine analysis. For measurement of cytokine production, the $\mathrm{CD}^{+} \mathrm{T}$ cells (purity, $>90 \%$ ) were isolated from the spleen of mice incubated with CT26 cells $\left(1 \times 10^{6}\right)$ for 21 days, as described previously (29). $\mathrm{CD}^{+} \mathrm{T}$ cells were sorted via negative selection using MACS CD3 MicroBeads (Miltenyi Biotec, Inc., Cambridge, MA, USA). Subsequently, $5 \times 10^{6} \mathrm{~T}$ cells were incubated with $5 \times 10^{5}$ Ag85A-DCs, mimic-DCs or no DCs in CT26-lysate for 2 days at $37^{\circ} \mathrm{C}$. The resulting solution was treated with Brefeldin A $(10 \mu \mathrm{g} / \mathrm{ml})$ for $5 \mathrm{~h}$ at $37^{\circ} \mathrm{C}$. Cells were cultured with anti-CD4/CD8 mAbs (cat. no. 23-2615; 1:1,000; BD Biosciences) for $30 \mathrm{~min}$ at $4^{\circ} \mathrm{C}$. The intracellular analysis was conducted using a flow cytometer (FACSCalibur; BD Biosciences). Data were analyzed using FlowJo software 7.6.1 (FlowJo, LLC, Ashland, OR, USA).

Cell proliferation assessment. To determine cell proliferation of Ag85A-DCs, cells were treated with $25 \mu \mathrm{g} / \mathrm{ml}$ mitomycin $\mathrm{C}$ at $37^{\circ} \mathrm{C}$ for $30 \mathrm{~min}$. Mimic-DC and non-transfected DC groups were used as controls. Cells were washed with PBS, following which cells were added to RPMI medium. Plates containing allogeneic $\mathrm{CD}^{+} \mathrm{T}$ cells $\left(2 \times 10^{5}\right.$ cells/100 $\mu \mathrm{l} /$ well, $>90 \%$ pure), collected from C57BL/6 mice via negative selection using MACS CD3 MicroBeads were originally incubated. T-cell proliferation was measured at 1,2 and 3 days by Cell Counting Kit 8 (CCK8) analysis. CCK8 was added to each well and cells were incubated for $4 \mathrm{~h}$ at $37^{\circ} \mathrm{C}$. The absorbance at $570 \mathrm{~nm}$ was measured using a microplate reader.

DCs pulsed with cancer cell lysate. Ag85A-DCs were incubated with tumor cell lysates through repeated freezing-thawing cycles. CT26 cells $\left(5 \times 10^{7} / 500 \mu \mathrm{l}\right)$ were lysed by rapid freezing in liquid nitrogen for $10 \mathrm{~min}$, followed by rapid thawing at $37^{\circ} \mathrm{C}$ water to dissolve the cells. This step was conducted in triplicate. Ag85A-DCs $\left(1 \times 10^{6}\right.$ cells $\left./ \mathrm{ml}\right)$ were cultivated in plates in RPMI-1640 with $10 \%$ fetal calf serum (Gibco; Thermo Fisher Scientific, Inc.) and $200 \mu \mathrm{l}$ of CT26 lysate was added, to obtain $2 \times 10^{7}$ cells. Cells were cultured for 2 days at $37^{\circ} \mathrm{C}$ and $\mathrm{CO}_{2}$ 
concentration of $50 \mathrm{ml} / \mathrm{l}$. The CT26 lysate alone served as the negative control.

Evaluation of cytotoxic T-lymphocytes in vitro. To verify the in vitro production of cancer-specific CTLs, $\mathrm{CD}^{+} \mathrm{T}$ cells were cultivated in RPMI with IL-2. Primed T-cells and CT26 tumor cells were used as effector cells and target cells, respectively. After 21 days of incubation, the target cell suspension $\left(4 \times 10^{5}\right.$ cells $\left./ \mathrm{ml}\right)$ was added to the plates, while the effector cells were prepared in various dilutions (effector-to-target ratio, 50:1). The supernatant was harvested after $20 \mathrm{~h}(5,000 \mathrm{x} \mathrm{g}$; $5 \mathrm{~min} ; 20^{\circ} \mathrm{C}$ ). Cytolytic activities against CT26 cancer cells were determined using a cytotoxicity measurement kit (HY-K0301; Beyotime Institute of Biotechnology, Haimen, China). $\mathrm{CD}^{+} \mathrm{T}$-cells releasing IFN- $\gamma$ were determined via flow cytometry (FCM), and the amount of IFN- $\gamma$ produced was measured using the mouse IFN- $\gamma$ Quantikine ELISA kit (MIF00; R\&D Systems, Inc., Minneapolis, MN, USA).

Tumor assessment. First, $1 \times 10^{6}$ CT26 cells/100 $\mu 1$ were injected into each $\mathrm{C} 57 \mathrm{BL} / 6$ mouse $(\mathrm{n}=6$, male) on the right back. DC vaccines were then administered at 1,7 and 14 days after injection with cancerous cells. Mice were administered with CT26 lysate-pulsed Ag85A-DCs (Ag85A-DC vaccine), CT26 lysate-pulsed mimic-DCs (mimic-DC vaccine), or CT26 lysate (control) into the tumors. Length, width and height $(\mathrm{mm})$ of the tumor was measured with a caliber every 3 days and the volume of tumors was calculated using the formula as previously (29): $\mathrm{V}\left(\mathrm{mm}^{3}\right)=0.52 \mathrm{x}$ length $\mathrm{x}$ width $\mathrm{x}$ height. The corresponding tumor weights were measured following sacrifice.

Statistical analysis. Data are presented as the mean \pm standard error of the mean. Significant differences among groups were evaluated by one-way analysis of variance, followed by Tukey's post-hoc test using SPSS software 17.0 (SPSS, Inc., Chicago, IL, USA). $\mathrm{P}<0.05$ was considered to indicate a statistically significant difference.

\section{Results}

Ag85A-transfected DCs. Transfection of DCs with Ag85A DNA was determined to be successful by RT-qPCR. As indicated in Fig. 1, Ag85A mRNA levels were significantly upregulated in Ag85A-transfected DCs compared with negative controls.

Ag85A transfection promotes the expression of primary surface markers in DCs. To fully understand the effects of Ag85A on DCs, the expression of primary surface markers was first evaluated in Ag85A-transfected DCs. FCM results revealed that the Ag85A-transfected DCs exhibited significantly increased expression of MHC class II, CD80 and CD86 compared with the mock-DCs or negative control DCs (Fig. 2). These findings indicated that Ag85A transfection promotes the expression level of primary surface markers in DCs.

Ag85A transfection promotes $T$-cell proliferation. Ag85A-transfected DCs were identified to be more effective in inducing allogeneic T-cell proliferation compared with

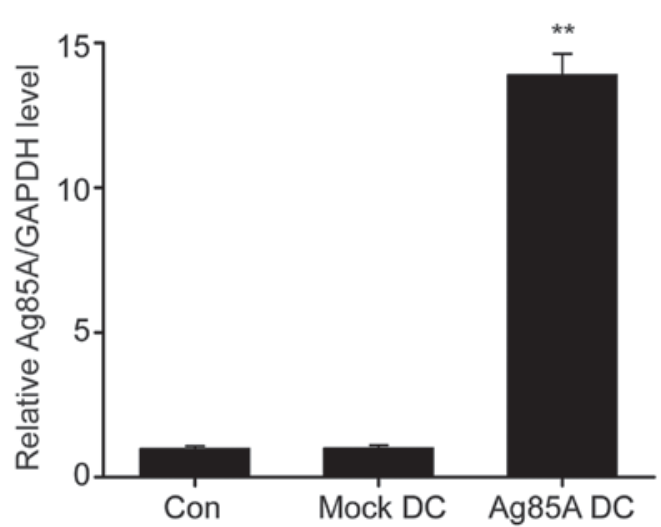

Figure 1. Determination of Ag85A mRNA expression levels by RT-qPCR. Ag85A expression in DC 2.4 cells transfected with pc-DNA3.1, DC2.4 plus pcDNA3.1 (mock-DC) or non-transfected DC 2.4 (Con) for $24 \mathrm{~h}$ was determined by RT-qPCR. Data are presented as the mean \pm standard error of the mean from three independent tests. ${ }^{* *} \mathrm{P}<0.01$ vs. mock-DC group. DC, dendritic cell; Ag85A, antigen 85A; Con, control; RT-qPCR, reverse transcription-quantitative polymerase chain reaction.

negative control DCs and mock-DCs. Ag85A-DC-induced T-cell proliferation was significantly increased at 48 and $72 \mathrm{~h}$ compared with mock-DCs and negative control DCs (Fig. 3). These findings suggested that Ag85A-DCs could trigger T-cell activation.

Ag85A transfection increases tumor-specific cytotoxicity of T-cells in vitro. T-cells incubated with CT26 lysate-pulsed Ag85A-DCs exhibited significantly enhanced cytolytic effects compared with those incubated with mock-DCs (Fig. 4A). Furthermore, Ag85A-DCs exhibited significantly increased IFN $-\gamma$ production compared with the CT26 lysate-pulsed mock-DCs and CT26 lysate alone (Fig. 4B). Furthermore, the proportion of IFN- $\gamma$-producing $\mathrm{CD}^{+} \mathrm{T}$-cells was investigated. As indicated in Fig. $4 \mathrm{C}$, the proportion of IFN- $\gamma^{+} \mathrm{CD}^{+}$cells was considerably higher in cells primed by CT26 lysate-pulsed Ag85A-DCs compared with cells primed by CT26 lysate alone or CT26 lysate-pulsed mock-DCs. These data demonstrated the potential of Ag85A-DCs to induce the activation of certain cytotoxic T-cells in vitro.

Intratumorally injected Ag85A-DC vaccine suppresses tumor development in mice. Finally, the effect of Ag85A-DCs on colorectal cancer growth was examined. As depicted in Fig. 5, mice administered with the Ag85A-DC vaccine had significantly smaller tumor weights and volumes compared with those administered with the mock-DCs vaccine. These findings indicate that the Ag85A-DCs vaccine effectively inhibited tumor growth in vivo.

\section{Discussion}

The current findings revealed that Ag85A-transfected DCs upregulated the expression of MHC-II, CD80 and CD86. Ag85A-DCs promoted allogeneic T-cell proliferation, elicited stronger activities against CT26 tumor cells and increased IFN- $\gamma$ production. In addition, treatment with the Ag85A-DCs vaccine considerably suppressed tumor progression in mice. Therefore, it was concluded that Ag85A-transfected DCs 
A
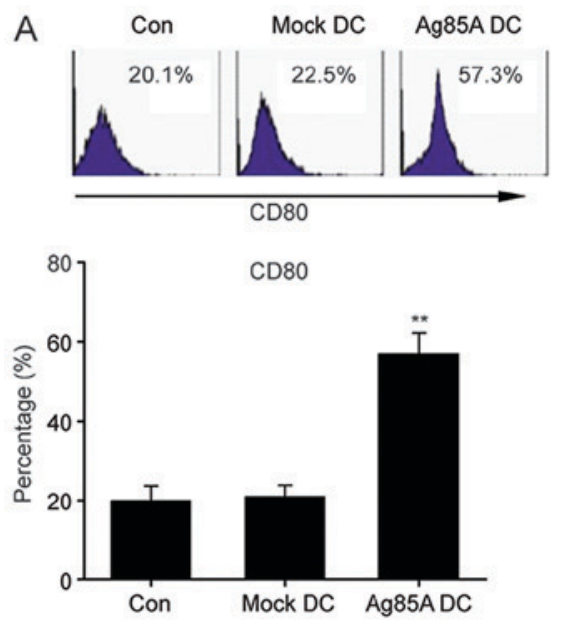
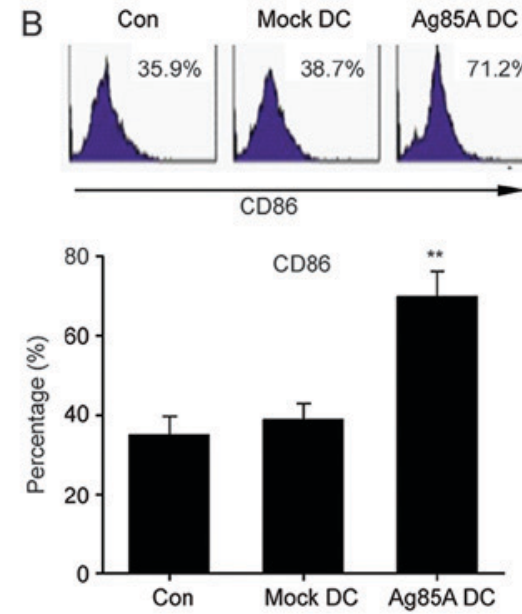
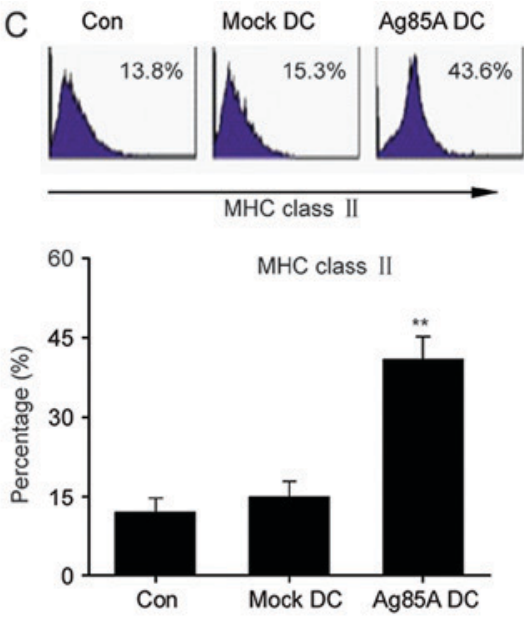

Figure 2. Ag85A transfection enhances the expression level of primary surface markers in DCs. Expression levels of (A) CD80, (B) CD86 and (C) MHC class II in Ag85ADCs, mock-DCs and controls were assessed via flow cytometry. Data are presented as the mean \pm standard error of the mean from three independent tests. ${ }^{* *} \mathrm{P}<0.01$ vs. mock-DC group. DC, dendritic cell; Ag85A, antigen 85A; Con, control; MHC, major histocompatibility complex.

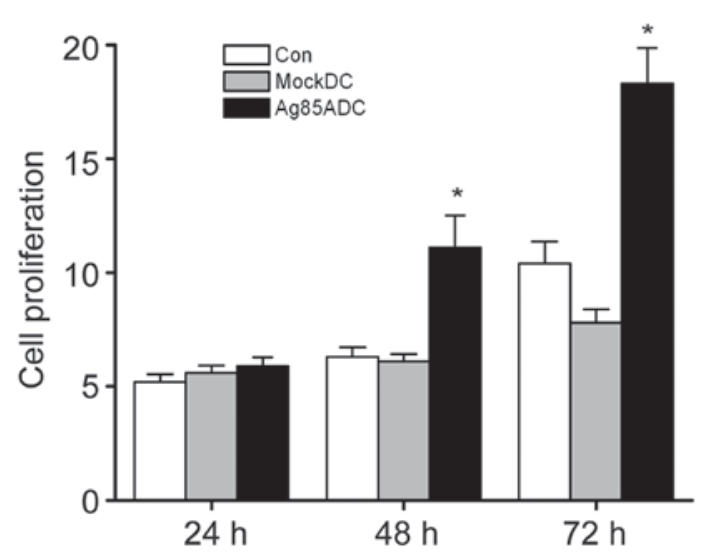

Figure 3. Ag85A transfection promotes T-cell proliferation. T-cell proliferation was measured by Cell Counting Kit 8 analysis on days 1, 2 and 3. Data are presented as the mean \pm standard error of the mean from three independent tests. "P<0.05 vs. mock-DC group. DC, dendritic cell; Ag85A, antigen 85A; Con, control.

enhanced immunity against colorectal carcinoma. The current results provided valuable insights and highlighted the potential use of Ag85A-transfected DC vaccines as an immunotherapeutic strategy for cancer treatment.

DCs are potentially effective for T-cell immunity. DCs primed with antigens migrate to lymphoid tissues to prime T-cells and activate the immune response by expressing co-stimulating and adhesive cell surface molecules. Host APCs play crucial roles in tumor antigen presentation (30). Nevertheless, various factors limit APC maturation and penetration into tumor tissues $(31,32)$. A previous study demonstrated that production and maturation of DCs are inhibited by multiple agents in patients with colorectal carcinoma (33). In the present study, it was demonstrated that Ag85A-transfected DCs strongly induced expression of primary surface markers, including MHC-II, CD80 and CD86, indicating that Ag85A promoted DC generation and maturation and enhanced anti-tumor immunity.

Ag85A is a key secretory protein in mycobacteria and thus acts as an effective stimulator of cell-regulated immunity (34,35). Reorganized Ag85A DNA was demonstrated to trigger strong immune reactions, leading to dramatic upregulation of Th1 cytokines (IFN- $\gamma$ and IL-2), which are crucial mediators of immunity. In turn, the Th1 cytokines functioned by stimulating cytotoxic cells and eliminating infected cells (36-38). In the current study, it was observed that Ag85A-DCs promoted allogeneic T-cell proliferation and increased IFN $-\gamma$ production. DCs transfected with Ag85A exhibited faster maturation both in terms of phenotype and function. Ag85A-DCs could effectively induce the activation of original T-cells, thereby acting as mediators between the internal and external immunities. Therefore, Ag85A-DCs represent a promising vaccine for immunotherapy of tumors and other diseases.

The application of DC-dependent tumor vaccination is effective as an auxiliary agent to stimulate cancer-specific immunity and represents a promising treatment strategy for cancerous diseases (39). Considering the development of drug resistance in late-stage tumor patients subjected to chemotherapy, the current findings contribute to the development of an alternative therapeutic strategy against tumors (40). DCs could be incubated with synthetic polypeptides and proteins derived from tumors. Whereas vaccines are developed to target one specific tumor antigen, antigens derived from tumor cell lysates can trigger a wide range of $\mathrm{T}$-cell responses against various tumor-related antigens (41). Vaccines containing DCs primed with tumor cell lysates have demonstrated strong potency against various tumor types in both laboratory and clinical settings $(42,43)$. In the current experiments, Ag85A-DCs and mock-DCs incubated with CT26 lysates triggered $\mathrm{T}$-cell activation against certain tumors and induced cytolytic activities targeting CT26 tumor cells. Furthermore, T-cells primed with CT26 lysate-pulsed Ag85A-DCs exhibited increased tumor-specific CTL activities compared with T-cells primed with mock-DCs. Intratumorally injected Ag85A-DC vaccines significantly inhibited tumor development in mice.

In conclusion, the current study demonstrated that Ag85A-DCs promoted DC maturation, triggered the activation of cancer-specific T-cells and promoted anti-tumor 
A

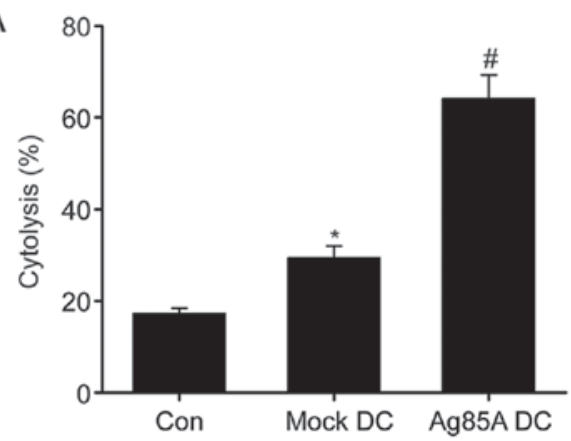

C

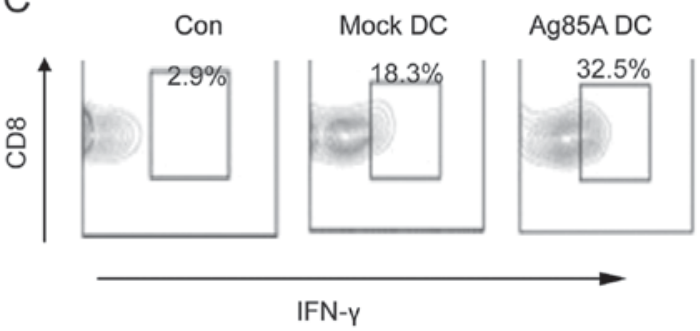

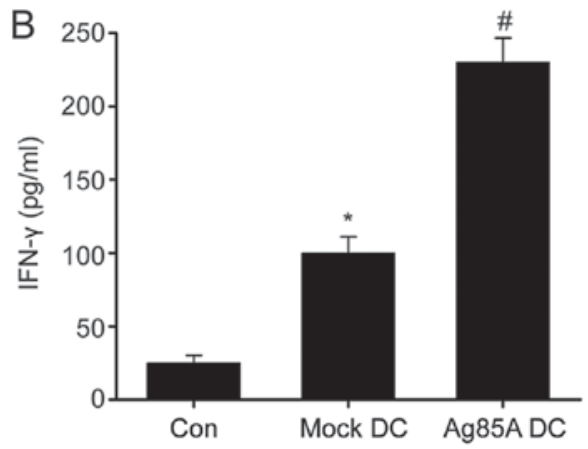

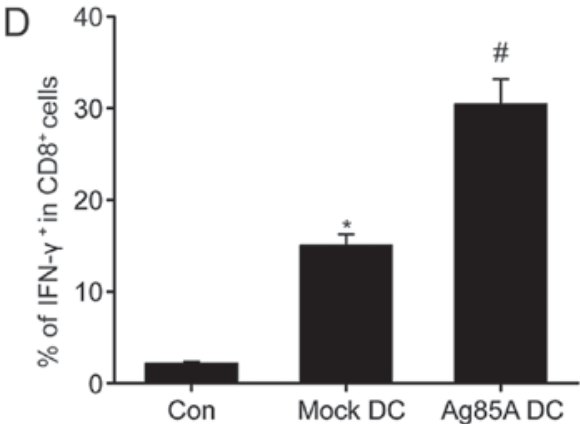

Figure 4. Ag85A transfection increases tumor-specific cytotoxicity of T-cells in vitro. (A) Cytotoxic T-lymphocyte activity was measured by targeting CT26 tumor cells in CT26 lysate-pulsed Ag85A-DCs (Ag85A DC), CT26 lysate-pulsed mock-DCs (mock-DCs) and CT26 lysate (Con) at an effector-to-target ratio of 50:1. (B) IFN- $\gamma$ production was assessed via ELISA. (C and D) Frequencies of CD8 ${ }^{+}$IFN- $\gamma^{+}$T cells were analyzed via flow cytometry. Data are presented as the mean \pm standard error of the mean from three independent tests; ${ }^{*} \mathrm{P}<0.05$ vs. control group; ${ }^{\prime} \mathrm{P}<0.05$ vs. mock-DC group. DC, dendritic cell; Ag85A, antigen $85 \mathrm{~A}$; Con, control; IFN, interferon.

A

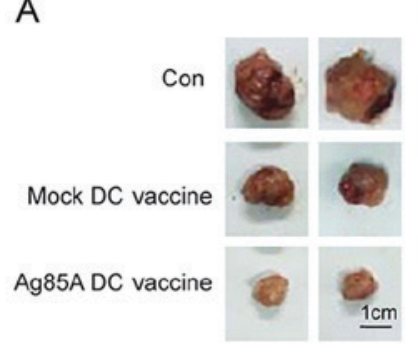

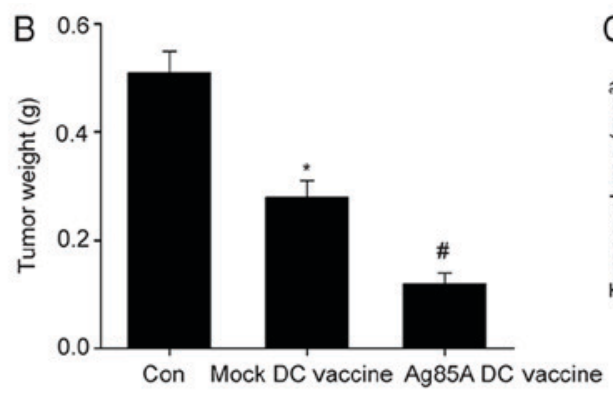

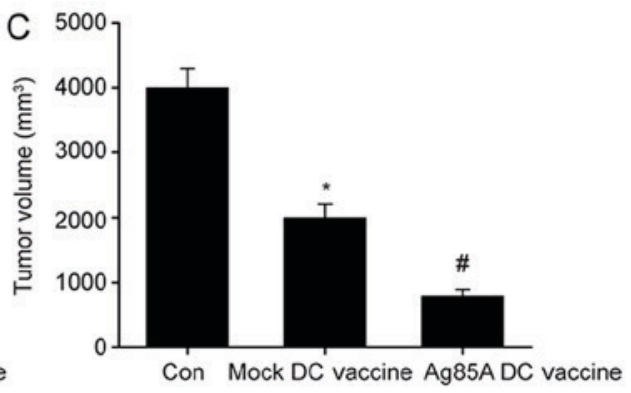

Figure 5. Administration of Ag85A-DC vaccine into tumors suppresses tumor development in mice. (A) Images, (B) weights and (C) volumes of resected orthotopic xenograft lab mice at 21 days after administration of tumor cells into the Ag85A-DC vaccine group, mock-DC vaccine group, and CT26 lysate group. Data are presented as the mean \pm standard error of the mean, $\mathrm{n}=6$. ${ }^{*} \mathrm{P}<0.05$ vs. control; ${ }^{\#} \mathrm{P}<0.05$ vs. mock-DC vaccine group. DC, dendritic cell; Ag85A, antigen $85 \mathrm{~A}$; Con, control.

cytolytic activities, thereby contributing to tumor growth inhibition. DCs in combination with the Ag85A gene could reinforce anti-colorectal carcinoma immunity. Ag85A-DC vaccines could serve as effective immunity activators and thus contribute to the development of therapies against cancers.

\section{Acknowledgements}

Not applicable.

\section{Funding}

This study was supported financially by grants from the National Natural Science Foundation of China (grant no. 31270972) and Characteristic Cross Disciplinary Construction Project of
Inner Mongolia University for the Nationalities 'Study on the prevention and therapy of brucellosis of Mongolian Medicine' in 2017 (grant no. MDXK007).

\section{Availability of data and materials}

All data generated or analyzed during this study are included in this article.

\section{Authors' contributions}

JZ and WG conceived the project, designed and performed the experiments, analyzed the data and wrote the manuscript. LZ performed experiments and analyzed the data. ZG and XJ performed the in vivo experiments. CL conceived the project, 
designed the experiments and revised the manuscript. All authors read and approved the final version of the document.

\section{Ethics approval and consent to participate}

The animals used in our study were treated in accordance with protocols approved by the Committee on the Ethics of Animal Experiments of China Medical University (Shenyang, China).

\section{Patient consent for publication}

Not applicable.

\section{Competing interests}

The authors declare that they have no competing interests.

\section{References}

1. Miyamoto Y, Zhang W and Lenz HJ: Molecular landscape and treatment options for patients with metastatic colorectal cancer. Indian J Surg Oncol 8: 580-590, 2017.

2. Bogach J, Levine O, Parpia S, Valencia M, Ruo L and Serrano P: Does the addition of biologic agents to chemotherapy in patients with unresectable colorectal cancer metastases result in a higher proportion of patients undergoing resection? A systematic review and meta-analysis. J Gastrointest Surg 22: 523-528, 2018.

3. Kwakman JJM, Vink G, Vestjens JH, Beerepoot LV, de Groot JW, Jansen RL, Opdam FL, Boot H, Creemers GJ, van Rooijen JM, et al: Feasibility and effectiveness of trifluridine/tipiracil in metastatic colorectal cancer: Real-life data from The Netherlands. Int J ClinOncol 23: 482-489, 2018.

4. Meyer B and Are C: Current status and future directions in colorectal cancer. Indian J Surg Oncol 8: 455-456, 2017.

5. Mohammadian M, Zeynali S, Azarbaijani AF, Khadem AM and Kheradmand F: Cytotoxic effects of the newly-developed chemotherapeutic agents 17-AAG in combination with oxaliplatin and capecitabine in colorectal cancer cell lines. Res Pharm Sci1 12 517-525, 2017.

6. Sun X, Han X, Xu L, Gao M, Xu J, Yang R and Liu Z: Surface-engineering of red blood cells as artificial antigen presenting cells promising for cancer immunotherapy. Small 13, 2017.

7. Richaud M and Bendriss-Vermare N: Cancer immunotherapy via systemic RNA delivery to dendritic cells. Med Sci (Paris) 33: 852-856, 2017 (In French).

8. Brown MC, Holl EK, Boczkowski D, Dobrikova E, Mosaheb M, Chandramohan V, Bigner DD, Gromeier M and Nair SK: Cancer immunotherapy with recombinant poliovirus induces IFN-dominant activation of dendritic cells and tumor antigen-specific CTLs. Sci Transl Med 9: pii: eaan4220, 2017.

9. Gilboa E: DC-based cancer vaccines. J Clin Invest 117: 1195-1203, 2007.

10. Chang WT, Chen HM, Yin SY, Chen YH, Wen CC, Wei WC, Lai P, Wang CH and Yang NS: Specific dioscoreaphytoextracts enhance potency of TCL-loaded DC-based cancer vaccines. Evid Based Complement Alternat Med 2013: 932040, 2013.

11. Draube A, Klein-González N, Mattheus S, Brillant C, Hellmich M, Engert A and von Bergwelt-Baildon M: Dendritic cell based tumor vaccination in prostate and renal cell cancer: A systematic review and meta-analysis. PLoS One 6: e18801, 2011.

12. Hsu FJ, Benike C, Fagnoni F, Liles TM, Czerwinski D, Taidi B, Engleman EG and Levy R: Vaccination of patients with B-cell lymphoma using autologous antigen-pulsed dendritic cells. Nat Med 2: 52-58, 1996.

13. Nakai N, Asai J, Ueda E, Takenaka H, Katoh N and Kishimoto S: Vaccination of Japanese patients with advanced melanoma with peptide, tumor lysate or both peptide and tumor lysate-pulsed mature, monocyte-derived dendritic cells. J Dermatol 33 462-472, 2006

14. Fong L, Hou Y, Rivas A, Benike C, Yuen A, Fisher GA, Davis MM and Engleman EG: Altered peptide ligand vaccination with Flt3 ligand expanded dendritic cells for tumor immunotherapy. Proc Natl Acad Sci USA 98: 8809-8814, 2001.
15. Brody JD and Engleman EG: DC-based cancer vaccines: Lessons from clinical trials. Cytotherapy 6: 122-127, 2004.

16. Engleman EG: Dendritic cell-based cancer immunotherapy. Semin Oncol 30 (3 Suppl 8): S23-S29, 2003.

17. Jakob T, Walker PS, Krieg AM, Udey MC and Vogel JC: Activation of cutaneous dendritic cells by $\mathrm{CpG}$-containing oligodeoxynucleotides: A role for dendritic cells in the augmentation of Th1 responses by immunostimulatory DNA. J Immunol 161: 3042-3049, 1998

18. Sparwasser T, Koch ES, Vabulas RM, Heeg K, Lipford GB, Ellwart JW and Wagner H: Bacterial DNA and immunostimulatory $\mathrm{CpG}$ oligonucleotides trigger maturation and activation of murine dendritic cells. Eur J Immunol 28: 2045-2054, 1998.

19. Belisle JT, Vissa VD, Sievert T, Takayama K, Brennan PJ and Besra GS: Role of the major antigen of Mycobacterium tuberculosis in cell wall biogenesis. Science 276: 1420-1422, 1997.

20. Lozes E, Huygen K, Content J, Denis O, Montgomery DL, Yawman AM, Vandenbussche P, Van Vooren JP, Drowart A, Ulmer JB and Liu MA: Immunogenicity and efficacy of a tuberculosis DNA vaccine encoding the components of the secreted antigen 85 complex. Vaccine 15: 830-833, 1997.

21. Huygen K, Content J, Denis O, Montgomery DL, Yawman AM, Deck RR, DeWitt CM, Orme IM, Baldwin S, D'Souza C, et al: Immunogenicity and protective efficacy of a tuberculosis DNA vaccine. Nat Med 2: 893-898, 1996.

22. Yuan W, Dong N, Zhang L, Liu J, Lin S, Xiang Z, Qiao H, Tong W and Qin C: Immunogenicity and protective efficacy of a tuberculosis DNA vaccine expressing a fusion protein of Ag85B-Esat6-HspX in mice. Vaccine 30: 2490-2497, 2012.

23. Tanghe A, Denis O, Lambrecht B, Motte V, van den Berg T and Huygen K: Tuberculosis DNA vaccine encoding Ag85A is immunogenic and protective when administered by intramuscular needle injection but not by epidermal gene gun bombardment. Infect Immun 68: 3854-3860, 2000.

24. Denis O, Tanghe A, Palfliet K, Jurion F, van den Berg TP, Vanonckelen A, Ooms J, Saman E, Ulmer JB, Content J and Huygen K: Vaccination with plasmid DNA encoding mycobacterial antigen 85A stimulates a CD4+ and CD8+ T-cell epitopic repertoire broader than that stimulated by Mycobacterium tuberculosis H37Rv infection. Infect Immun 66: 1527-1533, 1998.

25. Nakano H, Nagata T, Suda T, Tanaka T, Aoshi T, Uchijima M, Kuwayama S, Kanamaru N, Chida K, Nakamura $\mathrm{H}$, et al: Immunization with dendritic cells retrovirally transduced with mycobacterial antigen 85A gene elicits the specific cellular immunity including cytotoxic T-lymphocyte activity specific to an epitope on antigen 85A. Vaccine 24: 2110-2119, 2006.

26. Tarrant JP, Walsh MJ, Blanchard MC, Lee TD, Hoskin DW and Giacomantonio CA: Reduced tumorigenicity of B16-F10 mouse melanoma cells transfected with mycobacterial antigen 85A. Int J Oncol 25: 1693-1699, 2004.

27. Shen Z, Reznikoff G, Dranoff G and Rock KL: Cloned dendritic cells can present exogenous antigens on both MHC class I and class II molecules. J Immunol 158: 2723-2730, 1997.

28. Livak KJ and Schmittgen TD: Analysis of relative gene expression data using real-time quantitative PCR and the 2(-Delta Delta C(T)) method. Methods 25: 402-408, 2001.

29. Zhang P, Wang J, Wang D, Wang H, Shan F, Chen L, Hou Y, Wang E and Lu CL: Dendritic cell vaccine modified by Ag85A gene enhances anti-tumor immunity against bladder cancer. Int Immunopharmacol 14: 252-260, 2012

30. OkadaH,TaharaH,Shurin MR,Attanucci J,Giezeman-Smits KM, Fellows WK, Lotze MT, Chambers WH and Bozik ME: Bone marrow-derived dendritic cells pulsed with a tumor-specific peptide elicit effective anti-tumor immunity against intracranial neoplasms. Int J Cancer 78: 196-201, 1998.

31. Koirala P, Roth ME, Gill J, Piperdi S, Chinai JM, Geller DS, Hoang BH, Park A, Fremed MA, Zang X and Gorlick R: Immune infiltration and PD-L1 expression in the tumor microenvironment are prognostic in osteosarcoma. Sci Rep 6: 30093, 2016.

32. Eruslanov E, Daurkin I, Vieweg J, Daaka Y and Kusmartsev S: Aberrant PGE(2) metabolism in bladder tumor microenvironment promotes immunosuppressive phenotype of tumor-infiltrating myeloid cells. Int Immunopharmacol 11: 848-855, 2011.

33. Liu KJ, Wang CC, Chen LT, Cheng AL, Lin DT, Wu YC, Yu WL, Hung YM, Yang HY, Juang SH and Whang-Peng J: Generation of carcinoembryonic antigen (CEA)-specific T-cell responses in HLA-A*0201 and HLA-A*2402 late-stage colorectal cancer patients after vaccination with dendritic cells loaded with CEA peptides. Clin Cancer Res 10: 2645-2651, 2004. 
34. Meshkat Z, Teimourpour A, Rashidian S, Arzanlou M and Teimourpour R: Immunogenicity of a DNA vaccine encoding Ag85a-Tb10.4 antigens from Mycobacterium tuberculosis. Iran J Immunol 13: 289-295, 2016.

35. Mancha-Agresti P, de Castro CP, Dos Santos JSC, Araujo MA, Pereira VB,LeBlanc JG,Leclercq SY and Azevedo V: Recombinant invasive Lactococcus lactis carrying a DNA vaccine coding the Ag85A antigen increases INF- $\gamma$, IL- 6 and TNF- $\alpha$ cytokines after intranasal immunization. Front Microbiol 8: 1263, 2017.

36. Poecheim J, Barnier-Quer C, Collin N and Borchard G: Ag85A DNA vaccine delivery by nanoparticles: Influence of the formulation characteristics on immune responses. Vaccines (Basel) 4: pii: E32, 2016.

37. Stylianou E, Griffiths KL, Poyntz HC, Harrington-Kandt R, Dicks MD, Stockdale L, Betts G and McShane H: Improvement of BCG protective efficacy with a novel chimpanzee adenovirus and a modified vaccinia Ankara virus both expressing Ag85A. Vaccine 33: 6800-6808, 2015.

38. Metcalfe HJ, Steinbach S, Jones GJ, Connelley T, Morrison WI, Vordermeier M and Villarreal-Ramos B: Protection associated with a TB vaccine is linked to increased frequency of Ag85A-specific CD4(+) T cells but no increase in avidity for Ag85A. Vaccine 34: 4520-4525, 2016.

39. Chang CN, Huang YC, Yang DM, Kikuta K, Wei KJ, Kubota T and Yang WK: A phase I/II clinical trial investigating the adverse and therapeutic effects of a postoperative autologous dendritic cell tumor vaccine in patients with malignant glioma. J Clin Neurosci 18: 1048-1054, 2011.
40. Lou Q, Conway TJ Jr, Egilmez NK, Loyall JL, Bernstein SH, Kelleher RJ Jr and Bankert RB: B cell tumor vaccine enhanced by covalent attachment of immunoglobulin to surface proteins on dendritic cells. Clin Immunol 118: 66-76, 2006.

41. Fields RC, Shimizu K and Mulé JJ: Murine dendritic cells pulsed with whole tumor lysates mediate potent antitumor immune responses in vitro and in vivo. Proc Natl Acad Sci USA 95: 9482-9487, 1998

42. Dauer M, Herten J, Bauer C, Renner F, Schad K, Schnurr M, Endres $\mathrm{S}$ and Eigler A: Chemosensitization of pancreatic carcinoma cells to enhance T cell-mediated cytotoxicity induced by tumor lysate-pulsed dendritic cells. J Immunother 28: 332-342, 2005.

43. Schnurr M, Galambos P, Scholz C, Then F, Dauer M, Endres S and Eigler A: Tumor cell lysate-pulsed human dendritic cells induce a T-cell response against pancreatic carcinoma cells: an in vitro model for the assessment of tumor vaccines. Cancer Res 61: 6445-6450, 2001.

This work is licensed under a Creative Commons Attribution-NonCommercial-NoDerivatives 4.0 International (CC BY-NC-ND 4.0) License. 